\title{
Comparisons of Temperature Measurements from Local Weather Stations and the Tomato Plant Canopy: Implications for Crop and Pest Forecasting
}

\author{
Nita A. Davidson, L. Theodore Wilson', Michael P. Hoffmann' ${ }^{2}$ and Frank G. Zalom \\ Department of Entomology, University of California, Davis, CA 95616 \\ Additional index words. Lycopersicon esculentum, Heliothis zea, Spodoptera exigua, agrometeorology, degree day
models
}

Abstract. Temperatures recorded by weather stations and within the canopy of tomato (Lycopersicon esculentum Mill.) crops were compared in fields near Davis, Calif., during Summer 1983 (60 days) and 1987 (50 days). For both years, the average maximum and minimum temperatures, daily temperature ranges, degree days per day, and total accumulated degree days were compared. In 1983, the mean maximum temperature at the weather station did not differ significantly from that in the canopy, but the mean minimum temperature at the weather station was significantly lower than that in the canopy. In 1987, the mean maximum temperature at the weather station was significantly higher than that in the canopy, but mean minimum temperatures did not differ significantly. Temperature ranges were significantly narrower for the weather station toward the end of the 1983 season, and significantly wider for the weather station at midseason 1987. Comparisons of degree days per day showed significant differences between means at the weather station and in the canopy in 1983, and among those at the weather station and the two degree day calculation methods used for temperatures recorded in the canopy. Total accumulated degree days based on temperature records at the weather station were lower than those in the canopy in 1983 but higher in 1987. In 1987, the single sine degree day calculation method overestimated degree days compared to the 2-hr triangulation method. The phenology of the tomato crop as predicted by weather station temperatures indicated that tomato maturation was underestimated in 1983 and overestimated in 1987. The rate of development for hypothetical populations of Heliothis zea (Boddie) and Spodoptera exigua (Hübner) (Lepidoptera: Noctuidae) within the tomato crop was again underestimated in 1983 and overestimated in 1987, as based on temperature data of the weather station.

The developmental rates of crops, their pests, and associated natural enemies are regulated by the temperatures encountered through the course of a growing season (Willmer, 1986). As a result, the concept of physiological time (degree days) is now widely used as a driving variable for predictive phonological models used in agricultural systems. The calculation of degree days can be accomplished using a variety of techniques, but most assume that the growth rate of the crop or arthropod is linearly related to ambient temperature within the limits of specified lower and upper developmental thresholds (Wilson and Barnett, 1983). One popular method, which uses daily maximum and minimum temperatures, is the single sine method of Baskerville and Emlin (1968). Another method of calculating degree days is the triangulation or trapezoidal technique (Lindsey and Newman, 1956). Both methods can be adapted for use as 24-hr (single) methods that calculate degree days based on one maximum and one minimum temperature per day, or as $12-\mathrm{hr}$ or smaller interval methods if maximum and minimum temperatures are recorded at more frequent intervals. Increasing the frequency at which temperature data are collected will improve the precision of both techniques (Wilson and Barnett, 1983).

Fundamental to the accuracy of degree day calculations is the accuracy of the temperature data used. Temperature data may

\footnotetext{
Received for publication 19 Oct. 1989. We thank Robert Bugg, Susan Carl, Steve Schoenig, William Sims, Richard Snyder, and Joyce Strand for discussion, suggestions, and help with literature. Paul Gutierrez and Jan Smilanick assisted with data analysis. We also appreciate the careful review by Katharine B. Perry. The cost of publishing this paper was defrayed in part by the payment of page charges. Under postal regulations, this paper therefore must be hereby marked advertisement solely to indicate this fact.

'Dept. of Entomology, Texas A\&M Univ., College Station, TX 77843.

${ }^{2}$ Dept. of Entomology, Cornell University, Ithaca, NY 14853.
}

vary depending on the recording equipment and where the temperature records are taken relative to the location of the crop or arthropod. Temperature data are often obtained from weather stations that are located a considerable distance from the cropping system and in an entirely different environment. In a standard weather station, air temperature is measured in a shelter at a height of $1.5 \mathrm{~m}$ and the location is commonly surrounded by sod or weeds (Newman et al., 1959). Many studies have shown temperatures of the crop canopy to be modified by cultural practices, plant architecture, plant phenology, and humidity (Downey and Caviness, 1973; Lomas and Mandel, 1973; Sivakumar, 1986). In the course of a growing season, these modifications may lead to differences between temperatures within the crop canopy and those of the weather station environment. Therefore, it is important to measure the differences that may exist between temperature records of the weather station and those in the crop microclimate, and the impact of the differences when used in the phonological models.

We undertook the present study in processing tomato ( $L y$ copersicon esculentum Mill. ) fields in the Sacramento Valley of California. The primary objective was to determine how accurately local weather stations estimate temperatures occurring within the tomato crop. This goal was accomplished by comparing daily maximum and minimum temperatures, the daily temperature ranges (difference between maximum and minimum temperatures), and degree days per day as recorded at weather stations and within the tomato crop canopy. We also assessed the consequence of using temperature data obtained from both a local weather station and the tomato crop canopy in phonological models developed for processing tomato and

\footnotetext{
Abbreviations: AIR, above the soil surface; IN, inside the plant canopy; TOP top surface of the plant canopy.
} 
two of its major insect pests: the tomato fruitworm, Heliothis zea (Boddie), and the beet armyworm, Spodoptera exigua (Hübner) (Lepidoptera: Noctuidae).

\section{Materials and Methods}

\section{Temperature records}

In 1983, temperature within a tomato canopy was measured using a calibrated three-point thermograph with liquid and steel sensors (Model T603, Weathermeasure Corp., Sacramento, Calif.) installed in the center of a $3 \times 10 \mathrm{~m}^{2}$ planting of ' $\mathrm{UC}$ 82' processing tomatoes at the Univ. of California, Davis. The field was level,...with Yolo silty loam soil type, and $18.3 \mathrm{~m}$ above sea level in elevation. At the time of installation (12 July) the tomato crop canopy was $\approx 10.4$ to $0.5 \mathrm{~m}$ high. Each of the three probes extended $\approx 3.7 \mathrm{~m}$ from the thermograph (east, west, and south) and was shaded by a wooden boxlike shelter $(320 \times 160$ $\times 160 \mathrm{~mm}$ ). The probes were positioned parallel to the soil and suspended $0.15 \mathrm{~m}$ above soil level. Daily maximum and minimum temperatures were recorded for 60 days (13 July to 10 Sept.). Daily maximum and minimum temperatures for the same time period were also obtained from the University of California (Dept. of Land, Air, and Water Resources) touchtone station (Davis 1) (38'32" N 121'46" W, 18.3 m elevation). The Davis 1 station was located on level ground $\approx 0.5 \mathrm{~km}$ from the tomato planting and situated on bare soil (Yolo silty loam). Temperature data were recorded with a maximum-minimum thermometer $1.5 \mathrm{~m}$ above the soil surface, enclosed in a standard shelter.

In 1987, two microloggers (Model CR21, Campbell Scientific; Logan, Utah) were placed in a commercial field of processing tomatoes of various cultivars located $\approx 3.2 \mathrm{~km}$ east of Woodland, Calif. The Woodland field was level, with a soil type of Laugenour very fine sandy loam, and $9.1 \mathrm{~m}$ in elevation. Temperatures were recorded from inside the plant canopy (IN) at $0.25 \mathrm{~m}$ above the soil surface, the top surface of the canopy (TOP) at $0.50 \mathrm{~m}$ above the soil surface, and outside the canopy at $1.50 \mathrm{~m}$ above the soil surface (AIR). Five probes extended from each micrologger to the three strata for a total of three within and three on top of the canopy, and four above the soil surface. Because one of the TOP probes malfunctioned, data from this probe were not used. Temperatures from the nine probes were recorded every $2 \mathrm{hr}$ from 1 Aug. to 19 Sept. (50 days) with lapses on 2 Sept. at 0800, 1000, and 1200 HR for all probes. There were additional failures on 12 Sept. for three probes at $0200 \mathrm{HR}$. On 14 Sept. all probes malfunctioned at $1000 \mathrm{HR}$. Altogether, missing temperatures totaled AIR $=17$, $\mathrm{IN}=15$, and TOP $=16$. When only $1 \mathrm{hr}$ was missing, an average of the adjoining readings was used as an estimate for the missing value. For the missing data points on 2 Sept., a linear regression was generated by using the temperature at 0600 and $1400 \mathrm{HR}$, and then interpolating temperatures at 0800, 1000, and $1200 \mathrm{HR}$.

In 1987, maximum and minimum daily temperatures were also obtained from the following weather stations: Woodland (Woodland, 38'41" N 121'4” W, 19.8 m elevation); California Irrigation Management Information System automated (Davis 2, 38'32" N 121'47" W, 18.3 m elevation); and the Davis 1 station. The Woodland station, adjacent to a building, was 9.1 $\mathrm{km}$ from the Woodland tomato field on level land. Temperature data were recorded using an electronic maximum-minimum temperature sensor $1.8 \mathrm{~m}$ above the soil surface (Marvin silty clay loam soil type). The Davis weather stations, which were
$182.9 \mathrm{~m}$ apart, were $18.2 \mathrm{~km}$ from the tomato field. Because of their distance from the tomato field, temperature data from the two Davis stations were included only in the comparison of daily temperature ranges. The Davis 2 station was located on a level grassy tract with a soil type of Yolo silty loam and the area was irrigated more frequently than at the Davis 1 station. Temperature data were recorded at $1.5 \mathrm{~m}$ with a Fenwal electronic thermistor enclosed in a gill radiation shield.

\section{Data analysis}

In 1983 and 1987, we compared maximum and minimum temperatures and temperature ranges recorded at the weather station and in the tomato canopy using two-way analyses of variance (ANOVA). For each ANOVA, location of temperatures recording (weather station or canopy stratum) and time period were treated as factors. Each time period was 10 days long, and there were six and five time periods in 1983 and 1987, respectively. The 10-day time periods were included as replicates to account for the minor variations of temperature during the summer, when the weather of the lower Sacramento Valley is typically hot, dry, and sunny. In this way, we could measure among and within period differences, and evaluate the extent of variation of the temperature data for a given treatment.

In 1987, maximum and minimum temperatures were compared among the three strata (AIR, IN, and TOP) in the tomato canopy and at the Woodland weather station. The two Davis and one Woodland weather stations, along with the three canopy strata, were included in the daily temperature range comparison. The GLM Procedure of the SAS statistics package (SAS Institute, 1985) was used for each ANOVA, and Duncan's multiple range test for separation of means.

Degree days per day and accumulated degree days for the locations in the tomato crop canopy and at the weather station were calculated using the Univ. of California Integrated Pest Management (UC/IPM) computer system. The single sine method of degree day calculation was used when temperature data consisted of single daily maximum and minimum temperature records. However, canopy (AIR, IN, TOP) temperature records were taken frequently enough in 1987 to allow use of the 2 -hr triangulation method, adapted from Zalom et al. (1983) (Table 1). The average temperature of the three probes at each stratum was calculated at every 2 -hr interval. These average temperatures were then used to calculate degree days every $2 \mathrm{hr}$. The 12 degree day intervals were totaled for each stratum to yield

Table 1. Two-hour formulas for calculating degree days (DD) using the triangulation method. ${ }^{2}$

1. If $T_{\min }$ and $T_{\max }>T_{U}$, then $D D=T_{U}-T_{L} / 12^{y}$

2. If $T_{\min }$ and $T_{\max }<T_{U}$, then $D D=0$

3. If $T_{\min }$ and $T_{\max } \geq T_{L}$ and $\leq T_{U}$, then $D D=\left[\left(x_{i}-x_{i+1}\right) / 2\right] / 12$

4. If $T_{\min }<T_{L}$ and $T_{\max }>T_{L}$ and $<T_{U}$, then

$\mathrm{DD}=\left[\left(\mathrm{T}_{\max }-\mathrm{T}_{\mathrm{L}}\right)^{2} /\left(\mathrm{T}_{\text {max }}-\mathrm{T}_{\min }\right)\right] / 24$

5. If $T_{\max }>T_{U}$ and $T_{\min }>T_{L}$ and $<T_{U}$, then

$\mathrm{DD}=\left[\left(\mathrm{T}_{\min }+\mathrm{T}_{\max }-2 \mathrm{~T}_{\mathrm{L}}\right)-\left(\mathrm{T}_{\max }-\mathrm{T}_{\mathrm{U}}\right)^{2} /\left(\mathrm{T}_{\max }-\mathrm{T}_{\min }\right)\right] / 24$

${ }^{2}$ The 2-hr triangulation method calculates the area bounded by the minimum and maximum temperatures (recorded $2 \mathrm{hr}$ apart), and one or both of the developmental thresholds. [Adapted from Zalom et al. (1983)]. If the temperature at the initial time interval, xi, equals the temperature at the final time interval, $\mathrm{x}_{\mathrm{i}+1}$, then only the first three equations above apply.

'Where $\mathrm{T}_{\min }=$ minimum temperature and $\mathrm{T}_{\max }=$ maximum temperature for each 2-hr interval; $\mathrm{T}_{\mathrm{U}}=$ upper developmental threshold, and $\mathrm{T}_{\mathrm{L}}=$ lower developmental threshold. 
total degree days per day. Each day's calculations began at 0200 HR and continued until 0200 HR the following day. Two-way ANOVAs were performed for degree days per day for 1983 and 1987 with location (combined with degree day calculation method in 1987) and days treated as factors, Fisher's protected least significant difference test (Fisher's PLSD) was used for separation of means (Steel and Torrie, 1980).

The lower and horizontal upper developmental thresholds used were 10.0 and $34.4 \mathrm{C}$ for tomato, and 13.9 and $34.4 \mathrm{C}$ for $H$. zea (Wilson and Barnett, 1983). For S. exigua, only the lower developmental threshold of $12.2 \mathrm{C}$ was used (Hogg and Gutierrez, 1980).

\section{Impact on phonological models}

We compared models for the tomato crop using temperature data from weather stations and the crop canopy to determine to what extent the predictive capabilities of phonological models would be affected by the source of temperature data. Differences in accumulated degree days between the weather station and tomato canopy data were evaluated regarding the predicted maturation of the tomato crop. We also compared the single sine and 2-hr triangulation methods for calculations of accumulated degree days and applied these calculations to the phonological model for the tomato crop. Three hypothetical planting dates of 1 Mar., 1 Apr., and 1 May were established for both 1983 and 1987 to illustrate differences of accumulated degree days among variously timed tomato crops. Using the UC/IPM computer system, we calculated degree days per day from 1 Mar. through 1 Oct. for the Davis 1 (1983) and Woodland (1987) weather stations. The 1 Ott. date is sufficiently late to account for a possible delayed harvest for either year. The number of degree days per day within the canopy for this period was needed to compare the degree days per day, although monitoring of the canopy covered only 60 days in 1983 and 50 days in 1987. We regressed the known 60 (for 1983) and 50 (for 1987) degree days per day of-the canopy with the comparable degree days per day of the weather station to obtain degree days per day for the remainder of the days. For 1987, regressions were carried out using the degree days per day calculated with both single sine and 2-hr triangulation methods against the degree days per day of the weather station. The regression equations of the three lines were then used to generate degree days per day for the 1983 and 1987 canopies.

It was necessary to extrapolate the missing data for the canopy from the regression of the weather station and crop canopy to apply the models developed to predict crop and arthropod phenology. One of these phonological models, TOMDAT, developed by Wilson and Zalom (1986), predicts the degree days required for the crop to reach each of nine developmental stages (Table 2). In agreement with results obtained by Rudich et al. (1977) and based on 3 years of field studies, they found that high temperatures impaired fruit set and delayed crop maturation. Using the TOMDAT model, we estimated the number of days each hypothetical tomato crop would require to reach the stage when $75 \%$ to $90 \%$ of its fruit were ripe. For each of the three planting dates, accumulated degree days were compared between the weather station and the canopy. In 1987 we also made comparisons for the two degree day calculation methods.

Predictions of $H$. zea and S. exigua numbers within the crop canopy based on temperature data from the weather stations were made by comparing accumulated degree days between the weather stations and the crop canopy for 60 days in 1983 and 50 days in 1987 . We assumed the accumulated degree days
Table 2. Delay in tomato plant development (DD/day) at each phenological stage of tomato, resulting from daily temperatures $>32.2 \mathrm{C}$.

\begin{tabular}{lcc}
\hline \hline $\begin{array}{l}\text { Phonological } \\
\text { stage }\end{array}$ & $\begin{array}{c}\text { Total degree days } \\
\text { (base 10C) }\end{array}$ & $\begin{array}{c}\text { Delay in development } \\
\text { (DD/day) when } \\
\text { temperature }>32.2 C^{y}\end{array}$ \\
\hline Bloom & 185 & 11.05 \\
12.5-19 mm green fruit & 427 & 11.05 \\
31.75-38 mm green fruit & 495 & 11.05 \\
Mature green fruit & 557 & 11.05 \\
Pink fruit & 770 & 6.23 \\
10\%-30\% red fruit & 909 & 5.28 \\
30\%-50\% red fruit & 996 & 4.59 \\
$50 \%-75 \%$ red fruit & 1101 & 4.15 \\
$75 \%-90 \%$ red fruit & 1214 & 3.82 \\
\hline
\end{tabular}

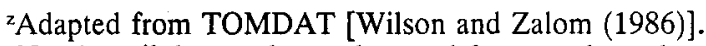

y Number of degree days subtracted from total number of degree days per day when maximum temperature exceeds $32.2 \mathrm{C}$. The constants representing the delays in development are used regardless of degree day calculation method.

within the canopy depicted the lepidopteran microenvironment more accurately than weather station-based estimates. Because weather station temperatures are generally used to estimate events in the canopy, we assigned the weather station calculations as the standard accumulated degree days. The ratio between the accumulated degree days of two sites (e.g., the weather station and canopy) and/or two calculation methods was designated the proportional error ( $\alpha$ error) by Eq. [1].

$$
\begin{gathered}
\alpha \text { error }=\left(\sum \text { DD method }-\Sigma \text { DD reference method }\right) / \\
\Sigma \text { DD reference method }
\end{gathered}
$$

where the reference method refers to the degree day calculation method used for the weather station $(1983,1987)$, or, likewise, the single sine method when the single sine and 2-hr triangulation methods were compared (1987). A positive $\alpha$ error denotes lower total accumulated degree days by the reference method, while a negative $\alpha$ error indicates that these measurements are higher. Although this designation is counter-intuitive, the positive error implies that the accumulated degree days are greater for the more accurate nonreference method.

The fecundities (total number of eggs per female laid at 25C) of both $H$. zea and S. exigua as obtained from Fye and McAda (1972) were then adjusted for the proportional error by Eq. [2].

$$
\text { Adjusted fecundity }=(\text { actual fecundity at } 25 \mathrm{C})^{(\alpha \text { error })}[2]
$$

Adjusted ratio $=$ adjusted fecundity/actual fecundity [3]

The actual fecundity ( $\mathrm{x}$ axis) was then plotted against the adjusted ratio (y axis) (as calculated from Eq. [3]), where actual fecundity is derived from the standard accumulated degree days. If, for example, the $\alpha$ error is negative, then the accumulated degree days of the weather station are overestimated relative to the canopy. Therefore, the fecundity predicted by weather station temperature data would overestimate actual numbers found in the canopy.

\section{Results and Discussion}

\section{Maximum and minimum temperatures}

In 1983, the mean maximum temperatures recorded in the canopy were significantly higher than those recorded at the local weather station for two of the 10-day intervals (12 to 31 Aug.) $(P<0.05)$. The mean minimum temperature within the canopy 

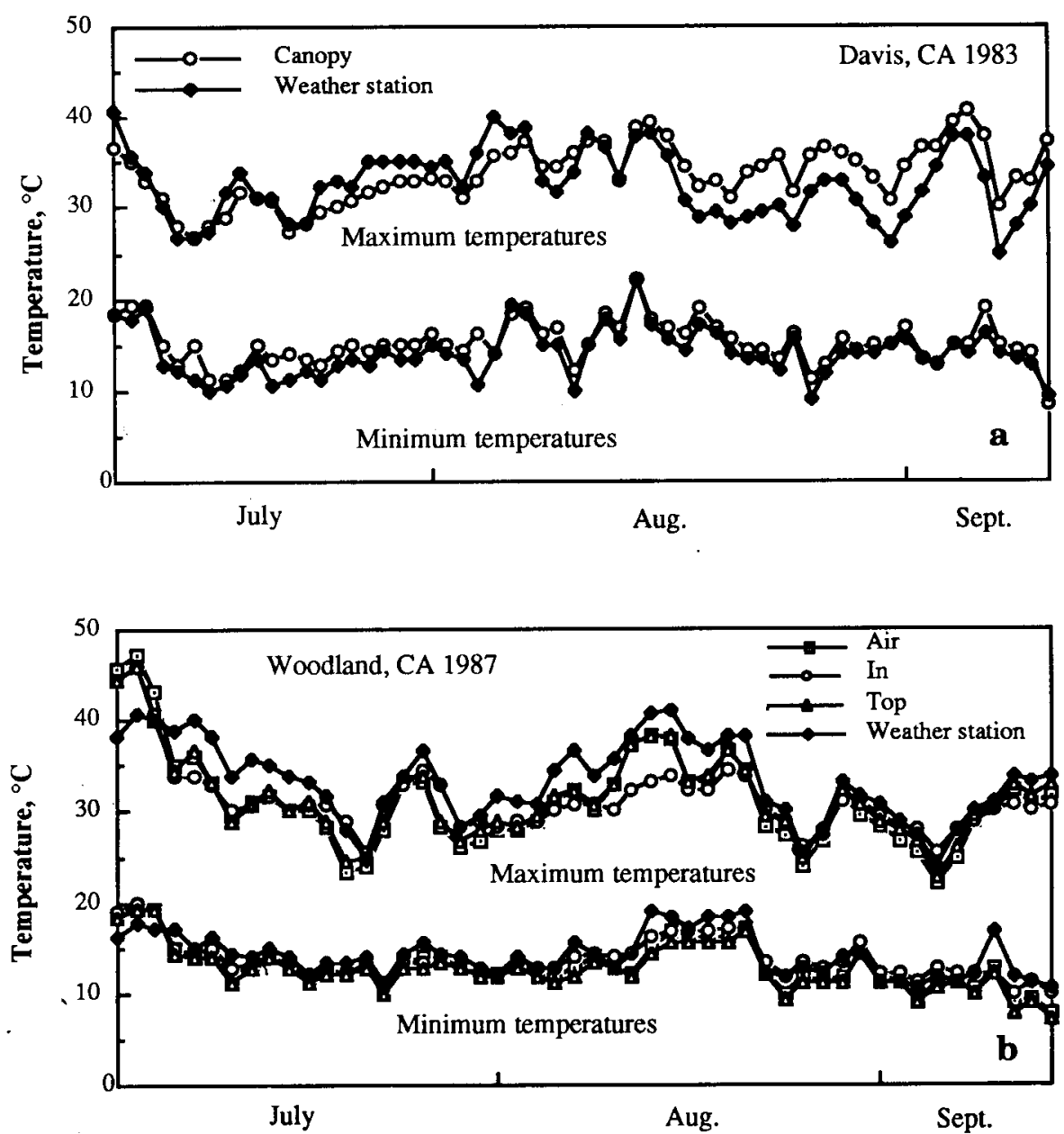

Fig. 1. Maximum and minimum temperatures as recorded by weather stations and within the canopy of a tomato crop for 1983 (a) and 1987 (b).

was significantly higher from 23 July to 1 Aug. (Fig. 1A). Over the 60-day period of comparison, the mean minimum temperature (15.0C) within the crop canopy was significantly higher than that recorded at the weather station $(14.0 \mathrm{C})$. Mean maximum temperatures over the same time period were not significantly different.

In 1987, maximum weather station temperatures were significantly higher than canopy temperatures at all strata (AIR, IN, TOP) from 21 to 31 Aug. (Fig. 1B). Minimum temperatures were also significantly higher for the weather station than for the TOP canopy stratum from 1 Aug. to 9 Sept. The maximum or minimum temperatures recorded at the three canopy strata did not differ significantly during any of the five periods. For the entire 50 days, however, the average maximum temperature recorded at the weather station (33.4C) was significantly higher than the average maximum temperatures of the tomato canopy at each of the strata (31.0C, AIR; 31.2C, IN; 31.5C, TOP).

The lower maximum and minimum temperatures of the weather station vs. the canopy toward the end of the 1983 tomato growing season may have been due to drying up of the tomato plants and the subsequent increase in soil exposure, resulting from the general senescing of leaves close to harvest. The overall warmer temperatures of the canopy at this time may have in part resulted from the termination of irrigation, which stopped 24 days before harvest, when the crop had reached the $10 \%$ red fruit stage. Irrigation usually is stopped $\approx 30$ days before tomato harvest to hasten ripening of fruit, and to enable equipment to enter the field (Brendler et al., 1985).

A late season rise in maximum temperatures of the canopy relative to the weather station was observed in 1983 but not in 1987. Because the Woodland weather station used in 1987 was adjacent to a building, its temperature data may have diverged more from those of the tomato canopy relative to the 1983 Davis weather station and canopy combination, when the weather station was located on a sod field. The Woodland weather station was also much farther from the Woodland tomato field $(9.1 \mathrm{~km})$ than the Davis weather station was from the Davis tomato field $(0.5 \mathrm{~km})$. Downey and Caviness (1973), working in a humid environment with soybean, also found that the canopy had lower maxima and higher minima than a nearby weather station. At the beginning of the growing season, in both irrigated and nonirrigated fields, maximum temperatures $0.15 \mathrm{~m}$ above the crop were higher than the maxima at $1.20 \mathrm{~m}$ and at a weather station $0.5 \mathrm{~km}$ away. Following irrigation, this situation was reversed.

In an experiment in a Michigan tomato field, overhead sprinkling lowered midday temperatures in the tomato canopy by $8 \mathrm{C}$ relative to a nearby weather station (van den Brink and Carolus, 1965). The temperature in the canopy fell $6 \mathrm{C}$ only 6 min after sprinkling began.

The increased availability of moisture due to irrigation may not be the only explanation of lower canopy maxima. Blad et al. (1978) and Weiss et al. (1980) found that a dense-canopied 
cultivar of bean had significantly lower canopy temperatures than an open-canopied cultivar. White mold (Sclerotinia sclerotiorum) infection was more prevalent in the dense-canopied cultivar regardless of irrigation frequency, although the opencanopied beans also developed disease when irrigated. Records from a nearby weather station would probably not reflect subtle differences in canopy temperature between cultivars, nor would they detect the higher temperatures of the canopy near severely diseased plants.

Canopy structure and its effect on canopy temperature have also been implicated in the incidence of Botrytis bunch rot of grapes (Savage and Sail, 1984). During morning, cluster temperatures of the less-open trellis were often lower than those in the more-open trellis. At evening, the more-open trellis cooled more abruptly than the less-open trellis.

\section{Temperature ranges}

In 1983, the mean canopy and weather station maximum and minimum temperature ranges differed significantly dur- ing most of the season (Fig. 2A). From 13 July to 1 Aug., the temperature range at the weather station was significantly higher $(P<0.05)$, but there was little difference from 2 to 21 Aug. The trend was reversed from 22 Aug. to 10 Sept., when the range of temperatures within the canopy was significantly higher.

The reversal of temperature ranges between the tomato canopy and weather station in 1983 was similar to the trend observed for maximum and minimum temperatures. In 1983, canopy temperature ranges were significantly lower through July, when denser foliage and periodic irrigation increased the humidity of the canopy, modifying temperature extremes. From late August through early September when the tomato plants reached maximum growth, the significantly higher temperature range of the canopy could again be explained by maturation of the tomato crop.

In 1987, the weather stations showed the widest range of temperatures, while the range of the strata of the tomato canopy was much narrower (Fig. 2B). The only significant difference
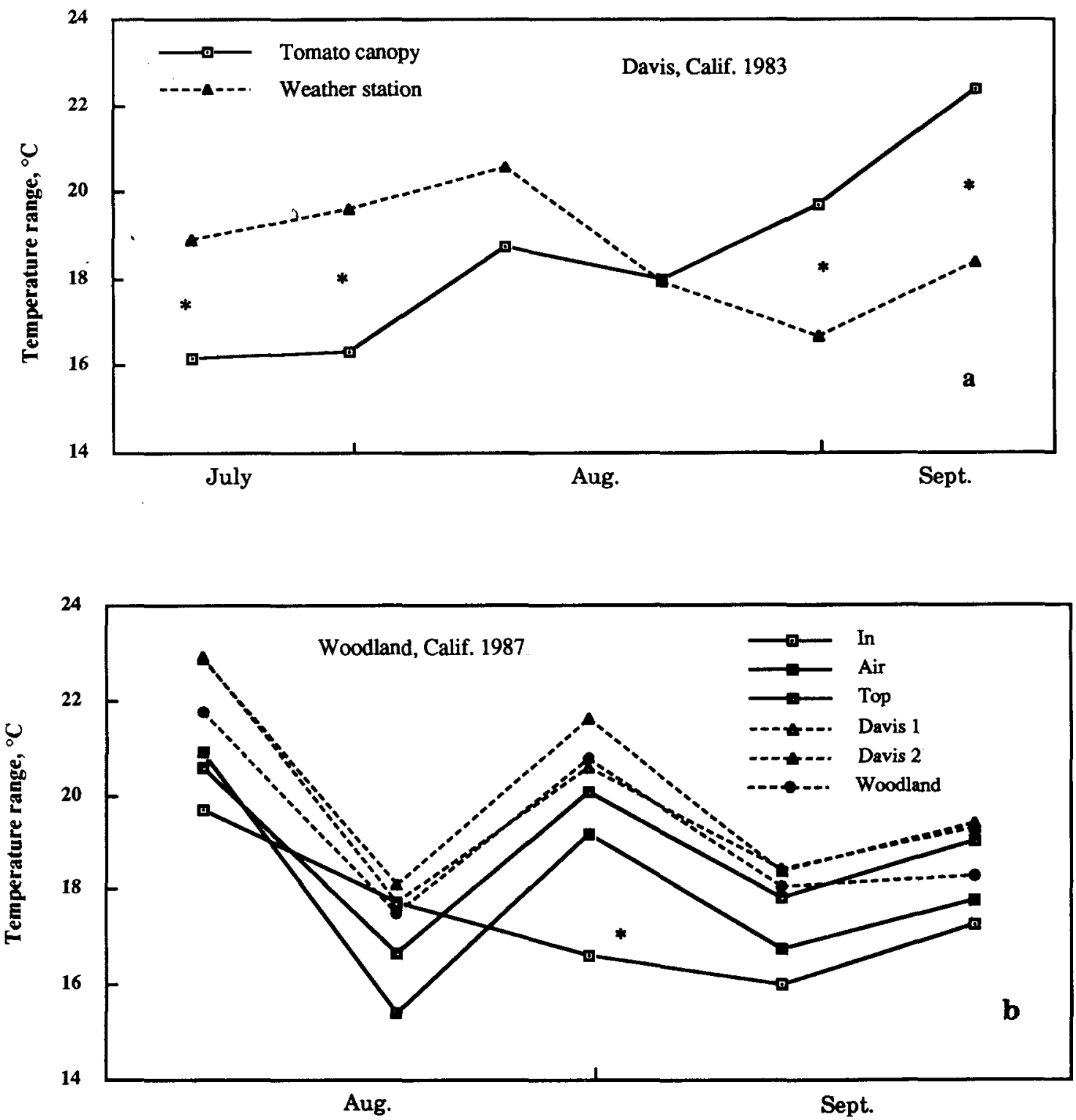

Fig. 2. Differences between weather station and tomato canopy temperature ranges. Temperature recordings are averaged for 10-day intervals for a total of 60 days for (a), and for 10-day intervals for a total of 50 days for (b). 
occurred from 21 to 30 Aug., when the IN stratum temperature range $(16.6 \mathrm{C})$ was much narrower than that of the other canopy strata and weather stations $(19.2$ to $21.6 \mathrm{C})(P<0.05)$. Unlike the reversal observed in 1983, the temperature range of the three weather stations remained higher than, the canopy temperature range throughout the growing season.

\section{Degree days and phonological models}

Degree days per day. In 1983, degree days per day for the weather station were lower than those for the canopy for 55 out of the total 60 days, differing from those of the canopy by 2 to 4 DD per day beginning in mid-August (tomato developmental thresholds) (Fig. 3A). The accumulated degree days within the canopy during the 60 days were 64.9 and 59.7 DD higher than those of the weather station when using the developmental thresholds for tomato or $H$. zea, respectively. A two-way ANOVA showed highly significant differences $(P<0.005)$ between degree days per day (tomato developmental thresholds) for the weather station $(\overline{\mathrm{x}}=13.12 \mathrm{DD} \pm 0.319 \mathrm{SE})$ and canopy $(\overline{\mathrm{x}}=$ 14.20 DD $\pm 0.228 \mathrm{SE}$ ) (Fisher's PLSD $=0.776$ ). Comparisons of means for degree days per day calculated at developmental thresholds for S. exigua and $H$. zea were also significantly different $(P<0.05)$.

Degree days per day in 1987 (tomato developmental thresholds) were significantly higher for the Woodland weather station than for the two methods used to calculate degree days within the canopy (Fisher's PLSD $=0.948, P<0.005$ ). The ranking of methods was: weather station $\overline{\boldsymbol{X}}=13: 49 \mathrm{DD} \pm 0.400 \mathrm{SE})$ $>$ single sine method; $(\vec{x}=12.29 \mathrm{DD} \pm 0.301 \mathrm{SE})>2-\mathrm{hr}$ triangulation method $\bar{X}=11.31 \mathrm{DD} \pm 0.308 \mathrm{SE}$ ) (Fig. 3B). The weather station data gave the highest estimate of degree days per day on 49 of 50 days. Using the means of degree days per day calculated at developmental thresholds for $S$. exigua and $H$. zea showed significance among all pairs except for those calculated at the $S$. exigua threshold: the means for the single sine $(\overline{\mathrm{x}}=10.24 \mathrm{DD} \pm 0.413 \mathrm{SE})$ and 2 -hr triangulation $(\overline{\mathrm{x}}=$ 9.20 DD $\pm 0.373 \mathrm{SE}$ ) methods within the canopy did not differ significantly (Fisher's PLSD $=1.152$ ).

Accumulated degree days. In 1983, total accumulated degree days were higher within the canopy relative to the weather station by 64.9 DD (tomato), 64.5 DD (S. exigua), and 59.7 $\mathrm{DD}(H . z e a)$ for the 60-days. Proportional ( $\alpha)$ errors for tomato $(8.3 \%)$, S. exigua $(9.7 \%)$, and $H$. zea $(10.6 \%)$ were calculated using Eq. [1], and considered the accumulated degree days at the weather station as the reference calculation method. Total accumulated degree days based on weather station temperatures vs. canopy temperatures for the 50-day 1987 period showed differences of $59.8 \mathrm{DD}$ for tomato and $59.0 \mathrm{DD}$ for $H$. zea. The $\alpha$ errors were $-8.9 \%$ and $-12.1 \%$ for tomato and $H$. zea, respectively. For measurements of canopy degree days, assuming a better accuracy for the 2-hr triangulation method, the single sine method overestimated accumulated degree days by $49.1 \mathrm{DD}(-7.9 \% \alpha$ error) for tomato, $52.3 \mathrm{DD}$ ( $-10.2 \% \alpha$ error) for $S$. exigua, and 47.2 DD (-11.1\% cerror) for $H$. zea.

Accumulated degree days as calculated by the triangulation method showed only slight differences among canopy strata (AIR, IN, and TOP). By 19 Sept. (50 days of accumulation), the IN stratum at 565 DD for tomato was 14.6 and 15.0 DD higher than the TOP and AIR strata, respectively. Using the H. zea threshold, the IN stratum (380 DD) was higher than the TOP stratum by 7.0 DD and the AIR stratum by 10.6 DD. The $\alpha$ errors for IN stratum degree days above the AIR stratum are $2.7 \%$ for tomato and $2.9 \%$ for $H$. zea.
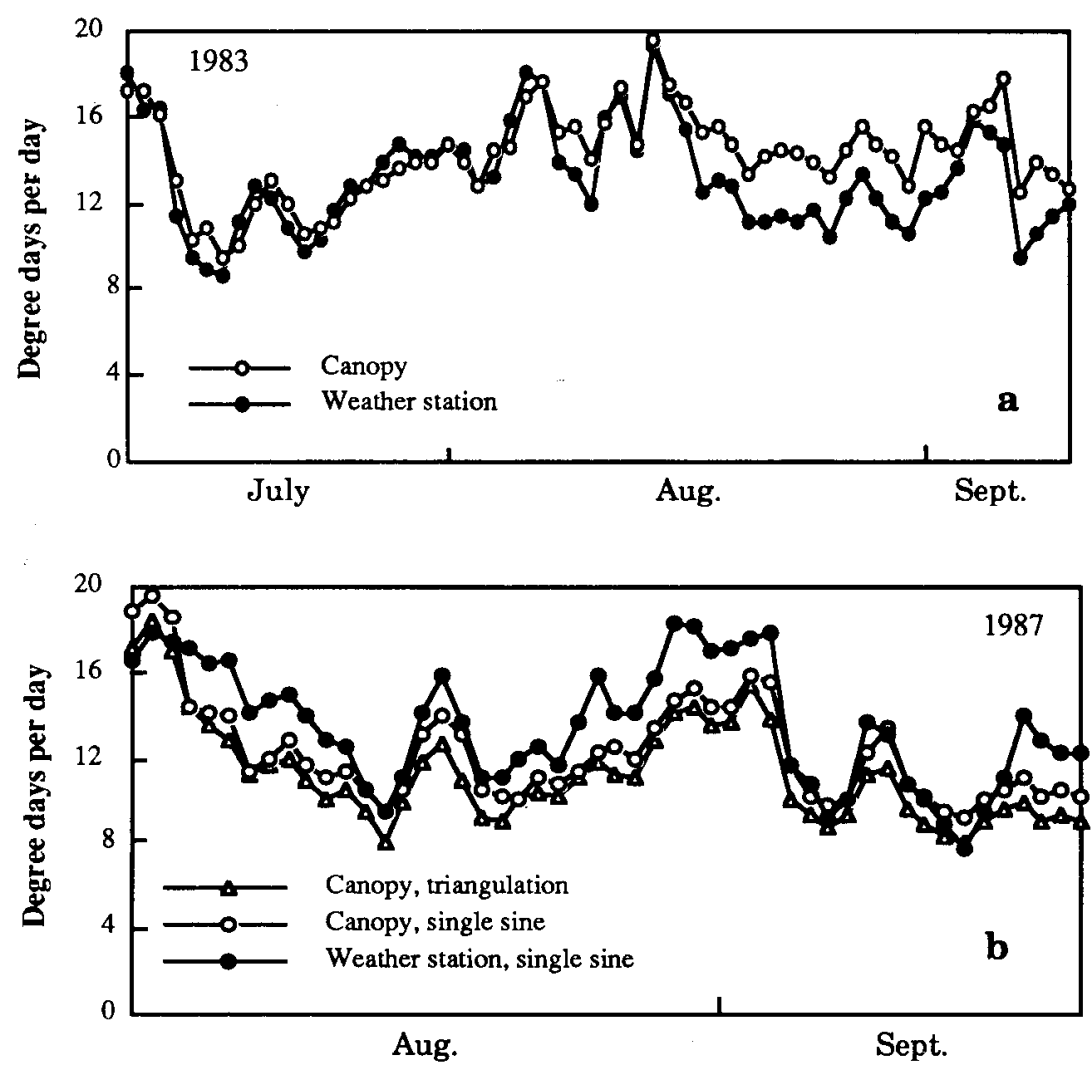

Fig. 3. Degree days per day using tomato plant developmental thresholds for (a) 13 July-10 Sept. 1983 and (b) 1 Aug.-19 Sept. 1987. 


\section{Degree day calculation methods and phonological models}

The single sine and single triangulation methods of calculating degree days are approximations used to predict the developmental rate of an organism; neither method is absolutely unbiased (Wilson and Barnett, 1983). Single degree day methods consider only the daily maximum and minimum temperatures, while methods considering 12- or 2-hr intervals calculate incremental degree days based on two or more sets of maxima and minima. Most of the degree day gain during a day is due to high temperatures, even though the portion of the maximum temperature above the upper developmental threshold is often ignored. Thus, additional time" increments will reduce overestimation.

In the studies reported herein, temperatures were frequently well above the upper developmental threshold of tomato and $H$. zea for several hours daily. Likewise, temperatures often fell below the $H$. zea lower threshold but rarely below the tomato plant lower threshold. A major limitation of most methods that calculate degree days is that detrimental effects due to extremes in high and low temperatures are ignored. For example, many cultivars of tomato abort their flowers if temperatures exceed $30 \mathrm{C}$ and remain above $20 \mathrm{C}$ at night (Rudich et al., 1977). Temperatures $>27.5 \mathrm{C}$ for several hours will result in fruit with poor color and reduced carotenoid content (Yakir et al., 1984). Arthropods can frequently survive constant high temperatures by behavioral or physiological thermoregulation, such as burrowing into the soil and curtailing their physical activities. However, the same temperatures can be detrimental to crops.

The TOMDAT model accounts for temperatures $>32.2 \mathrm{C}$ and delays tomato plant growth accordingly (Table 2). In 1983 the number of days to reach the maturation class of $75 \%$ to $90 \%$ red fruit occurred earlier based on degree days accumulated from the canopy vs. from the weather station for three hypothetical planting dates (Table 3). The differences between the

Table 3. Estimated phenology of tomato crops planted in 1983 and 1987 (1 Mar., 1 Apr., and 1 May) with and without adjustments for temperatures $>32.2 \mathrm{C}$.

\begin{tabular}{|c|c|c|}
\hline \multirow[b]{2}{*}{$\begin{array}{l}\text { Planting } \\
\text { date }\end{array}$} & \multicolumn{2}{|c|}{$\begin{array}{l}\text { Days from planting to } 75 \%-90 \% \\
\text { red fruit stage (date) }\end{array}$} \\
\hline & $\begin{array}{l}\text { Without adjustment } \\
\quad \text { for }>32.2 \mathrm{C}\end{array}$ & $\begin{array}{l}\text { With adjustment } \\
\text { for }>32.2 \mathrm{C}\end{array}$ \\
\hline \multicolumn{3}{|c|}{ 1983-Weather station } \\
\hline 1 Mar. & 155 (2 Aug.) & 164 (11 Aug.) \\
\hline 1 Apr. & 130 (8 Aug.) & 138 (18 Aug.) \\
\hline 1 May & 106 (14 Aug.) & 118 (26 Aug.) \\
\hline \multicolumn{3}{|c|}{ 1983-Canopy (single sine method) } \\
\hline 1 Mar. & 126 (4 July) & 135 (13 July) \\
\hline 1 Apr. & 110 (19 July) & 120 (29 July) \\
\hline 1 May & 96 (4 Aug.) & 108 (16 Aug.) \\
\hline \multicolumn{3}{|c|}{ 1987-Weather station } \\
\hline $1 \mathrm{Mar}$. & 129 (7 July) & 138 (16 July) \\
\hline 1 Apr. & 105 (14 July) & 118 (27 July) \\
\hline 1 May & 95 (3 Aug.) & 110 (18 Aug.) \\
\hline \multicolumn{3}{|c|}{ 1987-Canopy (single sine method) } \\
\hline 1 Mar. & 130 (8 July) & 139 (17 July). \\
\hline 1 Apr. & 111 (20 July) & 122 (31 July) \\
\hline 1 May & 102 (10 Aug.) & 116 (24 Aug.) \\
\hline \multicolumn{3}{|c|}{ 1987-Canopy (2-hr triangulation method) } \\
\hline 1 Mar. & 142 (20 July) & 155 (2 Aug.) \\
\hline 1 Apr. & 122 (31 July) & 134 (12 Aug.) \\
\hline 1 May & 112 (20 Aug.) & 124 (1 Sept.) \\
\hline
\end{tabular}

weather station and canopy were: 29 days, 1 Mar. planting; 20 days, 1 Apr. planting; and 10 days, 1 May planting (Fig 4A).

During 1987, when canopy maxima were lower than those of the weather station, comparisons of the weather station and canopy (sine method) for the three hypothetical planting dates estimated that fruit maturation according to canopy temperatures would be delayed by 1 day, 4 days, and 6 days, respectively, before reaching the $75 \%$ to $90 \%$ red fruit stage (Fig. 4B). Differences between estimates of fruit maturity predicted by canopy or weather station temperatures were smaller in 1987; however, the average maximum temperatures of the weather station vs. canopy were < 3C in 1987 for March through June, but 3.6 to 8.0C for the same period in 1983. Also in 1987, larger differences were found between the two degree day calculation methods within the canopy of 16 days, 12 days, and 8 days for the three respective planting dates.

Including or ignoring adjustments for temperatures $>32.2 \mathrm{C}$ only slightly changes the number of days to reach 1214 DD (75\% to $90 \%$ ripe fruit) for the weather station or the canopy. In 1983, a 9-day lag would be observed between the $75 \%$ to $90 \%$ red fruit stage (harvest date) estimated by the weather station vs. canopy temperatures. For most pairs of harvest dates for the three consecutive plantings, the number of days between the two methods increased as the planting date advanced. These differences amounted to 9 to 12 days in 1983 and 9 to 15 days in 1987. If high temperatures are ignored, the date of $75 \%$ to $90 \%$ ripening in 1983 using accumulated degree days at the weather station is $2 \mathrm{Aug}$. The expected date of this event for the canopy is 4 July, 29 days earlier. According to the TOMDAT model, the date of this event for the canopy would be 13 July (18 days). Ripening of fruit within the canopy would actually be $56 \%$ beyond that predicted by the data from the weather station, rather than the $90 \%$ predicted when ignoring the effect of high temperatures. Although adjusting for high temperature can change the projected ripening rate considerably, the most profound effect for 1983 was the discrepancy between weather station and canopy temperatures. In 1987, when monthly averages of maximum temperatures did not differ very much, the added fine-tuning of the 2-hr triangulation method highlighted the differences in estimated harvest dates.

Estimated rates of development of $H$. zea and $S$. exigua were notably different between the weather station and canopy microclimates for both years. In 1983, differences in accumulated degree days for the weather station predicted a $9.7 \%$ delay for $S$. exigua and $10.6 \%$ delay for $H$. zea. In 1987 , the weather station data contrasted with the canopy data (single sine) predicted respective advances of $-11.3 \%$ and $-12.1 \%$ for $S$. exigua and $H$. zea within the canopy.

The differences in accumulated degree days among strata and variations in calculation methods lead to very different predictions. For example, in 1983 the $10.6 \% \quad \alpha$ error would imply that $H$. zea fecundity in the warmer canopy would be 2188 eggs per female instead of 1047 eggs per female as predicted by the weather station data (Fig. 5). The ratio of 2188:1047 is 2.09, the adjusted ratio, which expresses the probable increase in fecundity in the canopy using weather station temperatures. The proportional error is a constant relationship and therefore can be applied to differences in the total number of generations. In 1987, the lower amount of accumulated degree days within the canopy than for the weather station implies that predicting fecundity using weather station data would overestimate the number of insects in the canopy. The adjusted ratios for the canopy relative to the weather station would be negative. 

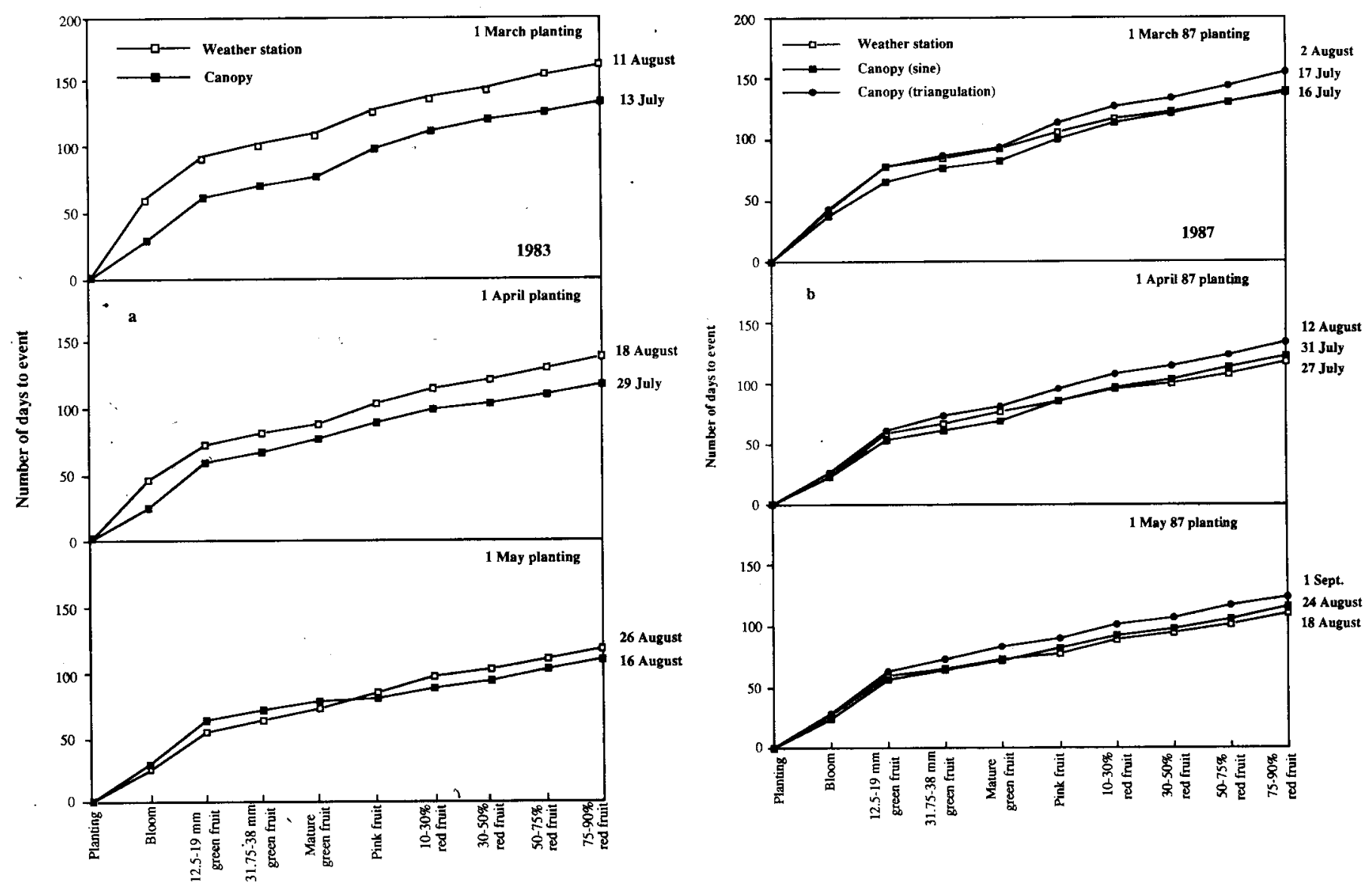

Fig. 4. Estimated phenology of tomato crops for 1983 season (a) and 1987 season (b) using 1 Mar., 1 Apr., and 1 May planting dates.

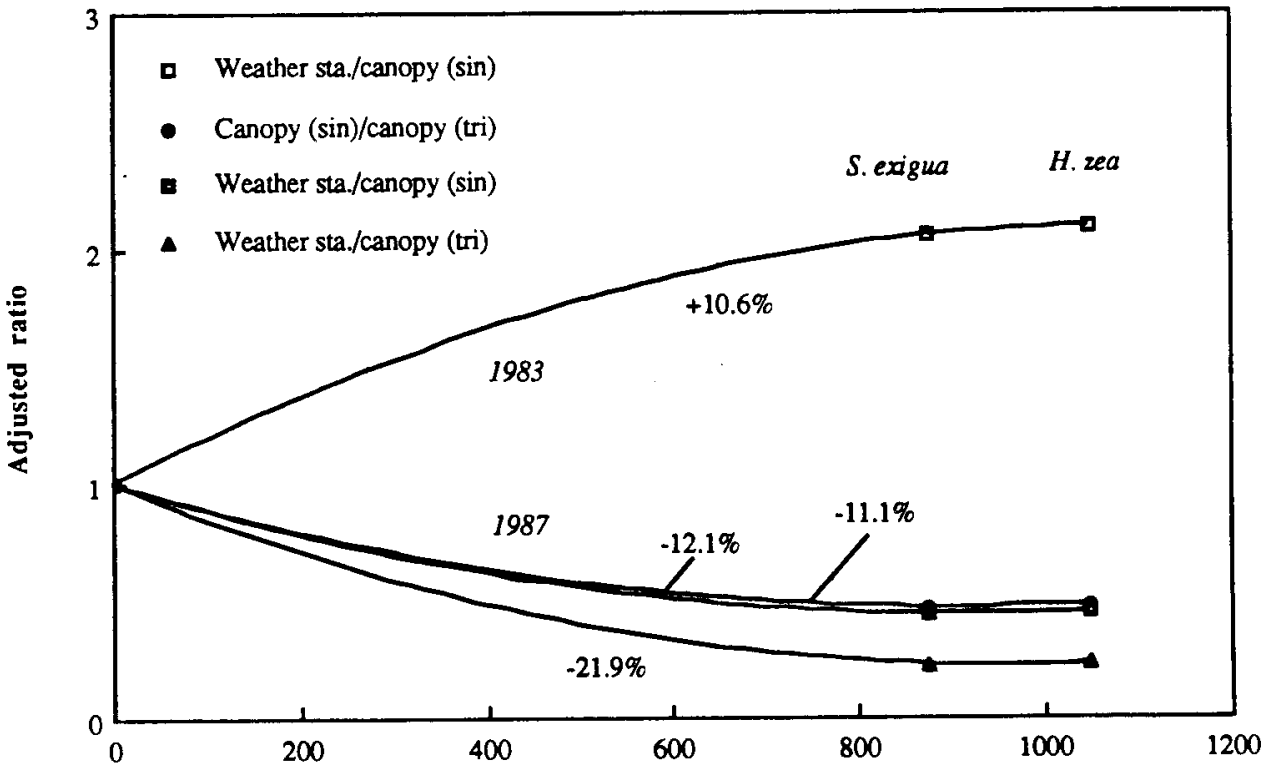

Fecundity

Fig. 5. Estimates of fecundity of Heliothis zea and Spodoptera exigua based on $\alpha$ errors between measurements of total accumulated degree days as noted in the legend. The first method of each contrasted pair is considered the reference method. ( $\sin =$ single sine degree day method; tri = 2-hr triangulation method).

Using temperature data from weather stations to predict phenological events in the crop canopy may lead to large errors. The crop itself may be highly influenced by the duration of high or low temperatures. For the tomato plant, degree days calculated from local weather stations using the single sine method do not reflect the delay in development predicted by the TOMDAT 
model at $32.2 \mathrm{C}, 2.2 \mathrm{C}$ below the upper developmental threshold. Therefore, basing ripening rate or plant growth solely on data obtained from a local weather station may be misleading.

Dependency upon weather station data can also erroneously estimate numbers of arthropods. Our study demonstrates that populations of $H$. zea or $S$. exigua would have been well above expected numbers in 1983 but would have fallen below expected numbers in 1987. Obviously, visual monitoring and sampling of the field would improve the accuracy further.

\section{Literature Cited}

Baskerville, G.L. and P. Emlin. 1968. Rapid estimation of heat accumulation from maximum and minimum temperatures. Ecology 50:514-517.

Blad, B. L., J.R. Steadman, and A. Weiss. 1978. Canopy structure and irrigation influence white mold disease and microclimate of dry edible beans. Phytopathology 68:1431-1437.

Brendler, R. A., B.B. Fischer, D.H. Hall, D.M. May, and N.C. Toscano (tech. coords.). 1985. Integrated pest management for tomatoes. Div. Agr. and Natural Resources, Univ. of California, Oakland. Pub]. 3274.

Downey, D.A. and C.E. Caviness. 1973. Temperature, humidity, and light studies in soybean canopies. Agr. Expt. Sta., Univ. of Arkansas. Bul. 784

Fye, R.E. and W.C. McAda. 1972. Laboratory studies on the development, longevity, and fecundity of six lepidopterous pests of cotton in Arizona. U.S. Dept. of Agr. (ARS), Tech. Bul. no. 1454:20-48.

Hogg, D.B. and A.P. Gutierrez. 1980. A model of the flight phenology of the beet armyworm, Spodoptera exigua (Lepidoptera: Noctuidae), in central California. Hilgardia 48: 1-36.

Lindsey, A.A. and J.E. Newman. 1956. Use of official weather data in springtime temperature analysis of an Indiana phonological record. Ecology 37:812-837.

Lomas, J. and M. Mandel. 1973. The quantitative effects of two methods of sprinkler irrigation on the microclimate of a mature avocado plantation. Agr. Met. 12:35-48.
Newman, J. E., R.H. Shaw, and V.E. Suomi. 1959. The agricultural weather station: its instruments, observations, and site requirements. Agr. Expt. Sta., Univ. of Wisconsin, Madison.

Rudich, J., E. Zamski, and Y. Regev. 1977. Genotypic variation for sensitivity to high temperature in the tomato: pollination and fruit set. Bet. Gaz. 138:448-452.

SAS Institute. 1985. SAS user's guide: Statistics. SAS Institute, Inc. Cary, N.C.

Savage, S.D. and M.A. Sail. 1984. Botrytis bunch rot of grapes: influence of trellis type and canopy microclimate. Phytopathology 74:65-70.

Sivakumar, M.V.K. 1986. Canopy-air differentials, water use and yield of chickpea in a semi-arid environment. Irr. Sci. 7:149-158.

Steel, R.G.D. and J.H. Torrie. 1980. Principles and procedures of statistics: A biometrical approach, 2nd ed. McGraw Hill, New York.

van den Brink, C. and R.L. Carolus. 1965. Removal of atmospheric stresses from plants by overhead sprinkler irrigation. Mich. Agr. Expt. Sta. Quart. Bul. 47:358-363.

Weiss, A., L.E. Hipps, B.L. Blad, and J.R. Steadman. 1980. Comparison of within-canopy microclimate and white mold disease (Sclerotinia sclerotiorum) development in dry edible beans as influenced by canopy structure and irrigation. Agr. Met. 22: 11-21.

Willmer, P.G. 1986. Microclimatic effects on insects at the plant surface, p. 65-80. In: B. Juniper and T.R.E. Southwood (eds.). Insects and the plant surface. Edward Arnold, London.

Wilson, L.T. and W.W. Barnett. 1983. Degree days: An aid in crop and pest management. Calif. Agr. 37:4-7.

Wilson, L.T. and F.G. Zalom. 1986. TOMDAT: A computerized crop management program for processing tomatoes (computer disk +12 pages). Copyright Regents of the Univ. of California.

Yakir, D., A. Sadovski, H.D. Rabinowitch, and J. Rudich. 1984. Effect of high temperature on quality of processing tomatoes of various genotypes ripened off the vine. Scientia Hort. 23:323-330.

Zalom, F. G., P.B. Goodell, L.T. Wilson, W.W. Barnett, and W.J. Bentley. 1983. Degree days: The calculation and use of heat units in pest management. Univ. of Calif., Coop. Ext., Lflt. 21373. 